Methods for Studying Infant Bilingualism

Krista Byers-Heinlein

Concordia University

To appear in:

The Cambridge Handbook of Bilingual Processing

Chapter 5

John W. Schwieter [Ed] 


\section{Methods for Studying Infant Bilingualism}

Bilingual infants are one of the most fascinating but also one of the most difficult groups of bilinguals to study. Infancy research is methodologically challenging due to infants' very limited behavioral repertoire. Infants cannot be asked to follow instructions, fill out questionnaires, or complete hundreds of trials. Thus the methods for studying bilingual adults (see Chapter 2) would fail miserably if applied to infants. Instead, researchers working with bilingual infants must use specialized methods that capitalize on their spontaneous behaviors.

For nearly 100 years (Ronjat, 1913), bilingual language acquisition was studied by observing infants' early productions (De Houwer, 1998). More recently, beginning with Bosch \& Sebastián-Gallés (1997), researchers have used experimental methods, in conjunction with parental report techniques, to understand language acquisition in bilingual infants. The adoption of these methods has corresponded with an explosion of interest in infant bilingualism (see Figure 1 for a yearly citation count of papers on infant bilingualism).

INSERT FIGURE 1 ABOUT HERE

This chapter will introduce methods and measures used in research with bilingual infants below the age of 2 years. These methods overlap considerably with techniques used to study language acquisition in monolinguals (Blom \& Unsworth, 2010; Hoff, 2012). Yet, research with bilingual infants presents its own challenges. This chapter will explore 
how infant research methods are applied to bilinguals, and how the results arising from such studies can be interpreted (see also Curtin, Byers-Heinlein, \& Werker, 2011 for a theoretical overview). The focus here will be on parental report and experimental techniques (see De Houwer, 1998 for information on case-study and diary methods). The chapter will begin with a discussion of how language background and vocabulary size can be assessed in bilingual infants using parental report. Next, behavioral and neuroimaging methods testing young bilinguals will be described using current examples from the infant bilingualism literature.

\section{Who is bilingual? Assessing language background}

At first blush, the term "bilingual infant" can seem puzzling. Adult bilinguals can be defined as "people who use two or more languages in their everyday lives" (Grosjean, 1989), or those "using or able to use two languages especially with equal fluency" (Collins English Dictionary). Yet infants typically produce little speech, so such definitions do not clearly apply them. Instead, the term "bilingual" or "monolingual" in infancy typically refers to infants' language exposure, rather than their language use or proficiency (De Houwer, 1990). Assigning infants to monolingual and bilingual groups for purposes of comparison is a common approach in experimental studies of early bilingualism. Yet, characterizing infants' language exposure, and determining how this information should be used to map infants into to "bilingual" and "monolingual" categories, is a challenging problem.

Even when infants can be reasonably described as "monolingual" or "bilingual", comparisons of these groups can be problematic. Although infants do not decide for 
themselves whether to grow up monolingual or bilingual, bilingualism is not randomly assigned. Depending on the population, bilingualism can co-vary with numerous factors. One of the most important of these is socioeconomic status. Bilingual families can be of systematically higher or lower socioeconomic status (SES) than monolinguals living in the same community (Morton \& Harper, 2009). Bilingual children also tend to be raised by bilingual parents, who may provide different types of input (i.e. accented speech, language mixing) than monolingual parents (Bosch \& Ramon-Casas, 2011; Byers-Heinlein, 2013). In some cases, differences between monolingual and bilingual infants will be due to these SES or input differences, rather than the fact of acquiring two languages per se (Byers-Heinlein \& Fennell, under review). Researchers in the field of early bilingualism must be careful before causation is attributed to bilingualism itself, rather than to other factors. The interaction between bilingualism and such factors may also be of interest. Nevertheless, researchers interested in early bilingualism still must assess language background to identify the population of interest. Most researchers rely on various forms of parental report to assess infants' language exposure, although to date there are no published studies comparing the validity of different measures. An obvious way to measure infants' language exposure is to simply ask parents for their best one-off guess, for example the percentage of time that their infant is exposed to different languages. However, this simplistic approach can often lead to inaccurate estimates, as parents do not always consider all aspects of their child's life, and sometimes report what they wish their child heard rather than what the child actually hears. Instead, many researchers use detailed parent questionnaires, which assess multiple facets of the child's 
life and language history (De Houwer \& Bornstein, 2003 for a diary-based method; see also Place \& Hoff, 2010). A particularly effective approach is to use a structured or semistructured interview, as many bilingual infants' language backgrounds are complex (Hoff \& Luz Rumiche, 2012). A skilled interviewer can elicit information that might be missed or misrepresented in a pen-and-paper questionnaire.

As an example, one popular language background questionnaire for infants was developed by Bosch \& Sebastián-Gallés (2001). The questionnaire is administered in an interview format, and has three sections. In the first section, the interviewer asks parents about the family's language background, including the native language of each of the parents, and the language that each parent speaks to the infant. In the second section, the interviewer walks the parent through a "day in the life" of the infant, quantifying the number of waking hours the infant is exposed to each language from different caregivers. Exposure from media such as television is excluded (Weisleder \& Fernald, 2011). If exposure changes on different days of the week, or has varied over the course of the child's life (e.g. upon entry to daycare), each component is noted separately. This information is used to compute a weighted average of the number of hours per week the child is exposed to each language, from which an overall percentage can be computed. Finally, once the parent has completed this second section and thus reflected in detail on the infant's exposure, in the third section the researcher asks the parent to provide a global estimate of the percentage of time that the child hears each language. The percentages from section 2 and section 3 are compared. If the two are widely discrepant, the researcher consults with the parents to identify the source of the difference. 
Once accurate information has been gathered about an infant's language background and exposure, researchers must decide whether or not an infant should be included as part of a "bilingual" group in a particular study. This decision is anything but straightforward, and depends on a myriad of factors including the onset of exposure (when the exposure began), the amount of exposure (how much exposure there is to each language), continuity of exposure (whether exposure has changed over time), contexts of exposure (how exposure is provided by different caregivers), and the particular languages of exposure (whether the particular language pair matters is important). Best practices for assessing bilingual infants' language exposure are summarized in Box 1. Researchers will need to consider each of these factors, discussed in turn below, in defining the inclusion criteria for their particular study.

\section{INSERT BOX 1 ABOUT HERE}

\section{Onset of exposure}

Bilingual infants can vary as to when exposure to their two languages began.

Exposure to two languages from birth implies building two systems concurrently, while exposure to a second language sometime after birth implies acquiring a new language in the context of a first language that has been partially acquired (Sebastián-Gallés, Bosch, \& Pons, 2008; Werker, 2012; Werker \& Byers-Heinlein, 2008).

Simultaneous bilinguals are the most frequently studied group of bilingual infants. Infants are considered simultaneous bilinguals if they have consistently encountered two 
languages from their caregivers on a daily basis, within the first few days or weeks of life

(De Houwer, 1995). One study of newborn infants also considered prenatal bilingual exposure, i.e. whether the mother spoke one or two languages during pregnancy (ByersHeinlein, Burns, \& Werker, 2010). Because it is considered unlikely that this very early exposure has lasting developmental consequences, prenatal exposure is not usually considered in studies of older infants.

Not all studies of bilingual infants have been limited to simultaneous bilinguals. For example, some studies have included infants whose first exposure to both languages occurred before age 6 months (e.g. Conboy \& Thal, 2006), while others have used a mixed group whose exposure to their second language began sometime between birth and ten months of age (e.g. Petitto et al., 2011). Still other studies have explicitly looked at early second language learners, for example infants whose exposure to their second language began at daycare (Von Holzen \& Mani, 2012).

Currently, there is little research on the impact of different onsets of exposure during the infancy period, but it is a strong possibility that simultaneous and early sequential bilinguals develop differently in at least some respects. Researchers working with bilingual infants should consider the age of onset of exposure to each language, as well as the months of experience the infant has had with each language. While more stringent inclusion criteria for onset and/or length of exposure will make participant recruitment more difficult, researchers should strongly consider how study results might be affected by combining groups of infants that vary in this respect. In groups that vary widely, it may be informative to include age of onset of exposure and/or length of 
exposure as an independent variable in statistical analyses. However, given the small samples typical of infancy research, potential effects will often be masked by other sources of variability.

\section{Amount of exposure}

The amount of exposure that children receive to their languages is a key determinant of whether they will grow up to be fluently bilingual (Pearson, 2008). This is therefore one of the most important, but also most challenging to measure, variables in determining whether an infant should be considered bilingual in the context of an experimental group. The most common quantification of amount of exposure is the percentage of time infants are exposed to each language (but see also studies that have used a Likert scale such as Garcia-Sierra et al., 2011; Shafer, Yu, \& Datta, 2011). As discussed above, the use of a detailed parental interview is an effective way to accurately estimate language exposure.

A perfectly balanced bilingual would be exposed to each language $50 \%$ of the time, but in practice this type of exposure is extremely uncommon. Typically, studies of bilingual infants set an inclusion criterion for the minimum percentage of time children should be exposed to each language. However, these minimums have varied widely in the literature: 40\% (Bosch \& Sebastián-Gallés, 1997), 35\% (Bosch \& Sebastián-Gallés, 2001), 30\% (Fennell, Byers-Heinlein, \& Werker, 2007; Singh \& Foong, 2012; Sundara, Polka, \& Molnar, 2008), 25\% (Byers-Heinlein \& Werker, 2009; Gervain \& Werker, 2013), 20\% (Ramon-Casas, Swingley, Sebastián-Gallés, \& Bosch, 2009), and 10\% (Hoff et al., 2012; Place \& Hoff, 2010). Thus, studies of bilingual infants have varied from being extremely conservative in 
their definition of "bilingual" to being extremely inclusive, and there is thus far no consensus in the field about what minimum is reasonable.

One consequence is that the minimums in some studies of "bilingual" infants overlap with the maximums of second language exposure for "monolingual" infants in other studies. For example, some studies of monolingual infants have included infants with up to 20\% (Fennell \& Werker, 2003; Poulin-Dubois, Blaye, Coutya, \& Bialystok, 2011) or even 25\% (Bosch, Figueras, Teixidó, \& Ramon-Casas, 2013) exposure to another language. In multicultural, multilingual areas, almost all infants are likely to have at least some exposure to another language, and it may be nearly impossible to recruit monolingual infants with strict exposure to a single language.

The crux of the problem is that language exposure ranges continuously (i.e. percentages can range from 0 to 100), but "monolingual" and "bilingual" describe discrete groups of infants. It is currently not known whether infants' underlying language abilities and development operate in a continuous or a discrete way relative to language exposure. Should children with small amounts of exposure to a second language be considered bilingual, or is that small amount of input disregarded by the system (Byers-Heinlein \& Fennell, under review)? Some studies of vocabulary have suggested that functions describing development relative to exposure are discontinuous (Pearson, Fernández, \& Oller, 1995; Thordardottir, 2011), in that there may be qualitative differences between more and less balanced bilinguals. However, the robustness and nature of these potential differences are not well understood. 
A consequence for researchers wishing to use the terms "monolingual" and "bilingual" is that they must decide whether infants in their study should be exhaustively categorized into these two groups. Some researchers take a conservative approach. For example, researchers might consider infants bilingual if they hear at least $25 \%$ of each of two languages, and monolinguals if they hear a single language at least $90 \%$ of the time. Thus, a child hearing 85\% English and 15\% French might not meet inclusion criterion for either group (see also Hoff \& Luz Rumiche, 2012). Because a complete and precise assessment of infants' language background is usually unfeasible before infants arrive in the lab, this will likely mean that some data might be collected but excluded because infants do not fit into either the monolingual or the bilingual group. Another approach is to test infants with a wide range of exposure, and analyze data using percent exposure as a continuous variable, rather than defining discrete monolingual and bilingual groups. Thus far this approach is uncommon.

A related challenge is how studies should handle infants exposed to more than two languages: trilingual and multilingual infants. Sometimes these infants are grouped together with bilinguals as long as they meet the inclusion criterion (i.e. an infant exposed to $40 \%$ English, $40 \%$ French, and $20 \%$ Spanish might be included in a bilingual group as there is at least $25 \%$ exposure to two languages). However, other studies exclude infants with more than a fixed amount (say 10\%) of exposure to a third language. There has been very little experimental research with groups of tri- or multilingual infants, however at least one study has found systematic differences between bilinguals and trilingual, 
suggesting that in some cases combining data from bilinguals and multilinguals might obscure important variation (Byers-Heinlein \& Werker, 2009).

\section{Continuity of exposure}

Infants' exposure to different languages often changes over time, for example due to new caregiving arrangements. Thus, even amongst seemingly straightforward populations such as simultaneous bilinguals, researchers need to consider the continuity of their language exposure. For example, imagine a 12-month-old who was initially exposed to two languages in a balanced proportion (50/50), but whose exposure to one language increased dramatically upon entering daycare at age 6 months (90/10). In this case, the infants' average exposure (70/30) might meet study inclusion criteria, but current exposure (90/10) might not. Studies with older children have suggested that both current as well as cumulative exposure might play a role in bilingual development (Unsworth, 2013). Study inclusion criteria should consider past, current, as well as cumulative exposure to each language.

\section{Contexts of exposure}

Bilingual infants also vary in how they encounter their two languages. The oneperson-one-language environment is often considered to be typical for bilingual infants (Barron-Hauwaert, 2004). However, research with large representative samples has suggested most bilingual infants have at least some exposure to bilingual adults (De Houwer, 2007; Döpke, 1998). Variables such as whether speech is provided by a native speaker (Place \& Hoff, 2010), the relationship between parental and community languages (De Houwer, 2007), how much bilingual parents mix their languages (Byers- 
Heinlein, 2013), and which of the two languages is maternal language (Ramon-Casas et al., 2009; Sebastián-Gallés \& Bosch, 2002) have all been shown to influence bilingual development. Infants may also differ on other experiential variables, for example the quality of their exposure to television, which is related to vocabulary size (Hudon, Fennell, \& Hoftyzer, 2013).

\section{Languages of exposure}

Studies with bilingual infants vary widely in the particular language being learned by the infants, and to date, very few studies of bilingual infants have been replicated across infants learning different language pairs. In some cases, experimental studies have used samples of bilingual infants all acquiring the same two languages. This is crucial in studies in which infants are tested in both languages (e.g. Bosch \& Sebastián-Gallés, 2001), or when the comparative properties of these languages are theoretically interesting (e.g. Bosch \& Sebastián-Gallés, 2003). However, other studies have used heterogeneous samples, grouping together bilingual infants who share one language, but vary on their other language (e.g. Byers-Heinlein \& Werker, 2009; Houston-Price, Caloghiris, \& Raviglione, 2010; Liu \& Kager, 2013). This is typically done in areas where the recruitment of a homogeneous sample is unfeasible.

The choice of whether to study a homogeneous or a heterogeneous bilingual group will depend on the research question, research design, stimuli, and on the types of bilingual infants available in the local population. The use of a heterogeneous sample will typically speed recruitment efforts by making inclusion criteria less stringent, but can make interpretation of study results more difficult. Few studies have directly compared 
infants from different language backgrounds, making it hard to predict when infants learning different language pairs might differ from each other. However, one study tested a group of heterogeneous (English-other) and two groups of homogeneous bilinguals (English-Chinese, English-French) on the same task with identical stimuli (Fennell et al., 2007). The three bilingual groups showed similar results, suggesting that at least in some cases, testing heterogeneous groups of bilinguals is an appropriate approach. At the same time, the use of heterogeneous groups without comparison to homogeneous groups has the potential to mask underlying variability across infants learning different language pairs.

\section{Assessing vocabulary size in bilingual infants}

Infant language researchers are often interested on how performance on experimental tasks relates to infants' developing vocabulary knowledge. The most common way to measure infant vocabularies is with a standardized instrument called the MacArthur-Bates Communicative Development Inventory (Fenson et al., 1993; 2007; see also Junker \& Stockman, 2002; Poulin-Dubois, Bialystok, Blaye, Polonia, \& Yott, 2012 for alternate approaches with bilingual infants). The CDI comprises two scales, the Words and Gestures scale (used from 8-18 months) and the Words and Sentences scale (used from 16-30 months).

A key part of the CDI is the vocabulary checklist. From a preset list of words, parents indicate the words their child understands/says (Words and Gestures) or says (Words and Sentences). Other aspects of the CDI assess early communicative gestures, symbol use, and emerging grammar, and some studies of bilinguals have investigated 
correlations amongst these different parts of the CDI (Conboy \& Thal, 2006; Hoff et al., 2012; Hurtado, Gruter, Marchman, \& Fernald, 2013).

The CDI has been adapted to dozens of languages, from Basque to Icelandic to Brazilian Sign Language. These adaptations are not simply translations, but take into account language and culture-specific differences. Each of these adaptations is independently normed, to account for variability in how different languages are acquired.

How can the CDI be used with bilingual infants, whose knowledge spans two languages? One popular method, particularly for homogeneous bilingual populations, is to administer two forms of the CDI, one in each of the child's languages (for a discussion see Pearson, 1998). Sometimes the same reporter completes each form, while other times different reporters complete each form, depending on who is the most familiar with the child's vocabulary in each language. Other approaches have multiple reporters fill out each form (De Houwer, Bornstein, \& Putnick, 2013), although it is difficult to compare across children with different numbers of reporters. Research suggests that the use of two CDIs with bilingual infants is a valid measure of their vocabularies (Marchman \& MartinezSussmann, 2002).

When heterogeneous groups of bilinguals are studied, assessing vocabulary is less straightforward, as in this case different infants are acquiring different language pairs. One approach is to use different pairs of CDIs for each infant, depending on the languages they are learning. However, as many languages do not yet have an adaptation of the CDI, and so such an approach is not always feasible in the diverse groups that are often tested. Another approach is to use a single adaptation of the CDI to assess both languages. For 
example, in one study, parents were asked to use the same form to indicate whether their child knew a particular word in English or its translation in the other language (HoustonPrice et al., 2010). However, this approach may reduce the validity of the measurement, as parents have to translate on the fly, and no adaptations are made for cultural and language-specific factors. A final approach for heterogeneous groups is to just use one CDI, for example the CDI measuring knowledge in the language of testing (e.g. ByersHeinlein \& Werker, 2009). However, this approach can only partially quantify bilinguals' language knowledge (Pearson, 1998), which may be useful in some cases (e.g.. investigating links between vocabulary knowledge in the language of testing and performance) but not in others.

Monolinguals' CDI vocabulary can be described by a single number for their comprehension and/or production vocabularies, and this can be compared to age- and gender-specific norms. There are currently no bilingual CDI norms. One reason is that the quantification of bilinguals' vocabulary size is complicated. Bilinguals' vocabulary can be measured in either language, thus a French-English bilingual has both an English and a French vocabulary size. Vocabulary size in a single language is typically smaller than a same-aged monolingual's vocabulary size (Bialystok, Luk, Peets, \& Yang, 2010). Some researchers have argued that it is necessary to measure bilingual infants' vocabulary knowledge across both of their languages, to gain a complete picture of language competence (Pearson, 1998; Pearson, Fernández, \& Oller, 1993). One way to do this is to simply sum the words known across the two languages, which yields a measure called total vocabulary size. 
A second way to measure a bilingual child's vocabulary knowledge is to count the concepts for which a child has a word, rather than all the words the child knows. This is called total conceptual vocabulary size. Total conceptual vocabulary size is different from the total vocabulary size, because bilinguals tend to know translation equivalents (crosslanguage synonyms; David \& Wei, 2008; De Houwer, Bornstein, \& De Coster, 2006;

Pearson et al., 1995; Poulin-Dubois et al., 2012; Sheng, Lu, \& Kan, 2011; Umbel, Pearson, Fernández, \& Oller, 1992). Figure 2 provides an illustration of single-language vocabulary, total vocabulary, and total conceptual vocabulary measurement in a hypothetical infant. It is not yet well understood how each of these vocabulary measures might differently to relate performance in experimental tasks. Researchers are recommended to look at relations of performance to each of these measures.

INSERT FIGURE 2 ABOUT HERE

\section{Behavioral methods for testing speech discrimination and preference}

Behavioral research methods are experimental approaches that rely on infants' well-understood tendencies to direct their attention to certain types of stimuli (Colombo \& Mitchell, 2009). An important application of these methods is in investigating infants' discrimination of and preference for different types of speech and language stimuli. As discussed below, behavioral techniques using sucking and looking-time measures have provided considerable insight into bilingual infants' nascent language knowledge. 


\section{High-amplitude sucking procedures}

High amplitude sucking is a behavioral research technique that can be used with infants in the first few months of life (Jusczyk, 1985). This method capitalizes on infants' natural sucking reflex. Infants are trained that every time they produce a strong or "highamplitude" suck they will hear a sound played from an adjacent speaker. Thus their sucking is taken as an index of their interest in different sounds. Variants of this technique can be used to test very young infants' discrimination of and preference for different types of language stimuli. Looking-based discrimination and preference procedures will be discussed in the next section.

One high-amplitude sucking study investigated language discrimination in newborns whose mothers were either monolingual English-speakers or bilingual EnglishFilipino speakers (Byers-Heinlein et al., 2010). Because fetal hearing is well developed in the last trimester, and the mother's voice in the womb is quite loud, these infants had several months of prenatal bilingual exposure. Infants were tested within a few days of birth in a maternity hospital. Infants were seated in a baby bath chair in their bassinet, and offered a sterilized pacifier. This was connected to a pressure transducer and computer that measured infants' sucking. There were two phases of the study: the habituation phase and the test phase. During the habituation phase, infants were played a sentence every time they produced a high-amplitude suck. Infants either heard all English sentences or all Filipino sentences during habituation. After their sucking declined to a pre-determined level, indicating habituation (roughly equivalent to boredom), they were tested with either new sentences in the same language or new sentences in the other 
language. Both monolingual and bilingual newborns increased sucking only to the sentences in the other language, suggesting that they discriminated English and Tagalog.

Research with a preference variant of the high-amplitude sucking procedure has also demonstrated that, while prenatal bilingualism does not alter early discrimination abilities, it does alter newborns' language preferences. Infants were played alternating minutes of English and Filipino sentences. Bilingual newborns showed equal interest in both of their native languages, sucking similarly during both minute types, while monolinguals preferred their single native language, sucking more during English minutes (Byers-Heinlein et al., 2010).

To date, these are the only published studies of bilingual infants that have used the high-amplitude sucking paradigm. One likely reason is that there are considerable challenges associated with implementing this paradigm. Newborn infants spend most of their time sleeping, and thus many infants recruited for high amplitude sucking studies never begin the procedure, fall asleep, or start crying partway through the study, yielding high attrition rates. Second, there are no commercially available systems on the market, so equipment for this procedure must be custom-built. As a consequence, this technique has recently lost popularity, while it is increasingly common for neuroimaging methods such as event-related potentials (Teinonen, Fellman, Näätänen, Alku, \& Huotilainen, 2009), and near-infrared spectroscopy (Gervain et al., 2011; Lloyd-Fox, Blasi, \& Elwell, 2010) to be used in studies of newborn infants. Neuroimaging methods will be discussed in greater detail in a later section. 


\section{Visual habituation procedures}

As infants become older, looking-time procedures become an age-appropriate and popular experimental method for studying language acquisition. By age 4 months, infants begin to have reasonable head and neck control, and they will visually orient towards a stimulus that interests them. Importantly for language researchers, infants will also orient to a visual stimulus when an accompanying auditory stimulus interests them.

Visual habituation procedures, so-called because infants' visual fixations are measured, are often used to assess infants' discrimination abilities. Infants are tested seated on their parents' lap in a soundproof testing room. Similar to habituation procedures using high-amplitude sucking, there are two main phases in this type of study: the habituation phase and the test phase. During the habituation phase, infants are presented with a repeated type of auditory stimulus, for example a particular syllable type. At the same time, their looking to an unrelated visual stimulus (e.g. a checkerboard pattern presented on a television monitor) is measured. Over time infants habituate, decreasing their looking time to the visual stimulus, implying that they have learned about and become bored with the stimuli. During the test phase, a new type of auditory stimulus is presented in an experimental condition, and the old type of stimulus is presented in a control condition (either within- or between-subjects). If infants can discriminate between the two types of stimuli, they are expected to look more to the changed (experimental) stimulus than to the unchanged (control) stimulus (for a discussion about implementing infant habituation procedures see Fennell, 2012). Habituation procedures have been used to test a wealth of abilities in bilinguals, from the discrimination of different phonetic 
categories (Sundara \& Scutellaro, 2010), to the discrimination of languages spoken by silent talking faces (Sebastián-Gallés, Albareda-Castellot, Weikum, \& Werker, 2012; Weikum et al., 2007).

For example, Sundara, Polka, and Molnar (2008) tested bilingual infants' discrimination of the French and English pronunciations of the /d/ sound. During habituation, infants saw a checkerboard on a television screen, while they heard one pronunciation of the syllable /da/, for example the French pronunciation. Infants' looking at the monitor was recorded online by an experimenter through a closed-circuit camera. Habituation continued until infants' looking to the television declined below $50 \%$ of the looking time for the longest three consecutive trials. At test, infants heard two types of trials. On control trials, infants heard the same type of /d/ sound as in habituation (e.g. the French pronunciation), while on experimental trials they heard the other /d/ sound (e.g. English pronunciation). Results showed that bilingual 10-12 month-olds looked longer when they heard the new stimulus type than when they heard the old stimulus type. This demonstrated that bilingual infants could discriminate English and French pronunciations of $/ d /$.

In an innovative variant of this procedure, bilingual infants were tested on their ability to make phonetic distinctions in each of their languages. Burns, Yoshida, Hill, and Werker (2007) noted that across French and English, there are intermediate sounds that are perceived as /p/ in French and /b/ in English. In their study, infants were habituated to tokens from this intermediate category, and then tested on their response to new tokens that were unequivocally English /p/'s and unequivocally French /b/'s. The results showed 
that young bilinguals discriminated both contrasts at 10-12 months of age, while sameaged monolinguals only discriminated the contrast that was meaningful in their own language.

\section{Preference procedures}

Rather than using habituation to test infants' discrimination abilities, another approach is to use a preference procedure. The logic of preference procedures is that if infants prefer one stimulus to another, then they can necessarily discriminate the two. Thus, preference procedures not only reveal what infants inherently like to listen to, but also provide an index of discrimination. Preference techniques have been fruitful for understanding bilingual infants' preference for their native languages over unfamiliar languages (Bosch \& Sebastián-Gallés, 2001), their nascent phonotactic (Sebastián-Gallés \& Bosch, 2002) and phonetic knowledge (Bosch \& Sebastián-Gallés, 2003; Sebastián-Gallés \& Bosch, 2009), and their ability to recognize familiar word forms (Vihman, Thierry, Lum, Keren-Portnoy, \& Martin, 2007).

The head-turn preference procedure is one popular such procedure (Fernald, 1985; Kemler Nelson, Jusczyk, Myers, Turk, \& Gerken, 1995). Infants sit on their parent's lap in a three-sided booth fitted with light bulbs (screens in more recent implementations) located in front of and to each side of the infant. Most studies begin with a familiarization phase where infants are exposed to a certain type of speech stimulus or speech stream. Unlike in habituation studies, the duration of familiarization is fixed. After familiarization, infants move to the test phase, where two different types of auditory test stimuli are be presented. Each test trial begins with a side light bulb blinking. Once infants initiate a head 
turn of 30 degrees or more, a test stimulus starts playing from a speaker hidden near the bulb, and continues until the infant looks away for at least 2 seconds or until the trial times out (e.g. 30 seconds). Infants' looking time is taken as a measure of their interest in their sound. Different trials are presented on different sides, although there is no contingency between side and the stimulus presented. Infants show their discrimination of the two types of test stimuli if they look longer during trials of one type than during trials of the other type.

In a recent study, Gervain and Werker (2013) used the head-turn preference procedure to study links between prosody (i.e. rhythm, stress, and intonation) and word order in bilingual 7-month-olds. Across the world's languages, there are systematic relationships between a language's prosody and its word order. For this reason, a language's prosody can provide infants with information about segmenting the speech stream. Gervain and Werker's study tested whether bilingual infants learning languages with different characteristic word orders could use prosodic information as a cue for segmentation.

During a familiarization phase, infants heard a 4-minute long speech stream. Importantly, without prosodic information the speech stream was ambiguous in terms of how it should be segmented, but prosodic information was included in the speech stream designed to cue infants to parse the stream in a particular way. After familiarization, infants heard 8 test trials of words with no prosodic information. Bilingual infants looked longer on test trials where words were grouped inconsistently with the familiarization stream's prosody, suggesting they had parsed the original stream accurately and were 
surprised by these incorrect words. Further, bilingual infants were flexible across the two types of prosodic patterns heard in each of their languages. However, monolingual infants only succeeded when they heard a familiarization stream consistent with their native language.

Rather than measuring total looking time, other studies have measured the time that it takes for infants to orient towards different types of stimuli, known as orientation latency. For example, Bosch and Sebastián-Gallés (1997) implemented a visual orientation latency measure to test whether Spanish-Catalan bilingual infants discriminated their maternal language from an unfamiliar language. Infants were seated in a small testing room, facing a computer monitor and two loudspeakers monitors covered with a picture of a woman's face. Each trial started with colorful images presented on the central monitor to draw the infants' attention. Next, infants heard sentences from either their maternal or an unfamiliar language play from one of the side loudspeakers. Videos were coded offline to measure how long it took infants to look towards the loudspeaker on each trial. Based on previous work, the authors expected infants to orient more quickly to a familiar stimulus over an unfamiliar stimulus. Indeed, monolingual infants did orient more quickly to their native language than to the unfamiliar language. Surprisingly, bilingual infants showed the opposite pattern, orienting more slowly to their maternal language than to the unfamiliar language. This difference in orientation latency still demonstrated infants' discrimination of the two languages, however the direction of the difference was unexpected. One tentative explanation was that bilingual infants tried to 
ascertain which of their two languages was being spoken before orienting towards the familiar stimulus.

The above study provides a good illustration of how interpreting the results of preference studies can be more difficult than interpreting the results of habituation studies. In habituation studies, infants are expected to dishabituate to a novel stimulus, as infants have been exposed to the first stimulus precisely to the point of losing interest in it (the definition of habituation). That is, if they are truly habituated, infants should always show greater interest in a novel than in a familiar stimulus. In preference procedures, infants can display either a novelty preference (longer/faster looking at novel test trials) or a familiarity preference (longer/faster looking at familiar test trials). The direction of preference depends on the complexity of the stimulus, the amount of familiarization, and the developmental level of the infant (Hunter \& Ames, 1988). Thus any difference in looking at the two trial types is taken as evidence for discrimination, even though it is difficult to predict the direction of the difference a-priori. Null results (equal interest in two test trial types) are particularly hard to interpret, as a lack of preference does not necessarily imply a lack of discrimination.

\section{Anticipatory eye movement procedures}

Anticipatory eye movement procedures are a recently-developed measure of discrimination in infancy (McMurray \& Aslin, 2004). In such procedures, infants learn to associate an auditory stimulus type with a visual reinforcer. Typically, two different types of auditory stimuli paired contingently with the left and right sides of a visual display. If infants can anticipate where the visual reward will appear after hearing only the auditory 
stimulus, this implies that they both can discriminate the two types of stimuli, and can learn the associated rule.

For example, Albareda-Castellot, Pons, and Sebastián- Gallés (2011) tested Spanish-Catalan bilingual infants' discrimination of a vowel contrast that exists only in Catalan, /e/- / $\varepsilon /$. Infants saw an Elmo cartoon loom on the screen, then disappear behind a t-shaped occluder. When infants heard the word /dedi/, Elmo reappeared on the right side of the occluder. When infants heard the word /drdi/, Elmo reappeared on the left side of the occluder. The side of association was counterbalanced across infants. Researchers coded whether infants' eye movements correctly anticipated the side of the cartoon's reappearance, which could only be done successfully if infants discriminated the /e/- / $\varepsilon /$ sound. Bilinguals were successful in this procedure, anticipating the visual reward at above-chance levels. The results of this study raise the possibility that anticipatory eye movements might be particularly sensitive for bilingual infants, as in a previous study using familiarization-preference bilinguals had not demonstrated discrimination of this contrast (Bosch \& Sebastián-Gallés, 2003).

In a different variant of anticipatory looking, bilingual infants' ability to inhibit an anticipatory response has been used to investigate cognitive advantages of bilinguals relative to monolinguals. Kovács \& Mehler (2009) taught 7-month-old infants that an auditory cue would predict the appearance of a visual reinforcer on one side of the screen. Once infants had learned the rule, they switched the side of appearance of the reward. Thus, infants who had been trained to look to the right side to see the reward now had to inhibit this response and look to the left. Both monolingual and bilingual 
infants were able to learn the first rule, but bilinguals showed an advantage when the rule was switched. This was taken as evidence that bilingualism confers enhanced inhibitory control even in infancy.

\section{Behavioral methods for testing word recognition and word learning in older infants}

\section{The Switch procedure}

The Switch procedure was developed by Werker and colleagues (1998) as a habituation-based method for studying infant word learning in the lab. In a habituation phase, infants repeatedly encounter two word-object pairings: word A - object A, word B

- object B. Once infants' looking to the stimuli has declined and they have been habituated, they proceed to the test phase. There are two types of test trials: a Same trial that presents a familiar pairing (e.g. word A- object A), and a Switch trial that presents a novel pairing (e.g. word A - object B). A key aspect of this design is that on both the Same and the Switch trial, the auditory stimulus and the visual stimulus are familiar, but on the Switch trial the pairing itself is novel. If infants have successfully learned the association between the object and the word, they are expected to look longer on the Switch trial than on the Same trial.

As an illustration, Fennell, Byers-Heinlein, and Werker (2007) used the Switch task to test bilingual infants' ability to learn the minimal pair bih and dih. On half of habituation trials, infants heard the word bih paired with a novel crown-shaped object, and on the other half infants heard the word dih paired with a novel molecule-shaped object. At test, infants saw two trials in a counterbalanced order. On the Same trial, infants saw one of the previously habituated pairings, either bih-crown or dih-molecule pair. On the Switch 
trial, infants saw a novel pairing, either bih-molecule, or dih-crown. Twenty-month-old bilingual infants succeeded on this task, but 14- and 17- month-old bilinguals did not. As other research has shown that bilingual infants can learn a word-object pairing at 14 months if the words are dissimilar-sounding (Byers-Heinlein, Fennell, \& Werker, 2013), this implies that minimal pair word learning can be a challenge for young bilinguals, just as it is for monolinguals (Stager \& Werker, 1997). Other studies which have varied properties of the auditory stimuli have shown that in some cases bilinguals succeed in minimal pair word learning at the same age as monolinguals (Mattock, Polka, Rvachew, \& Krehm, 2010).

Intermodal preferential looking procedure

The intermodal preferential looking procedure is commonly used to test infants' comprehension of words and sentences (Golinkoff, Hirsh-Pasek, Cauley, \& Gordon, 1987; Golinkoff, Ma, Song, \& Hirsh-Pasek, 2013). In this paradigm, infants' fixations to two sideby-side pictures (a target and a distractor) are measured as they hear a word or sentence referring to the target. If infants look at the target more than the distractor (often measured relative to a silent baseline), this indicates comprehension. Intermodal preferential looking tasks have been used with bilingual infants as young as 17 months (Byers-Heinlein \& Werker, 2009; Houston-Price et al., 2010), although recent methodological advances with monolinguals suggest that variants of the task can show word knowledge as young as 6 months (Bergelson \& Swingley, 2012; 2013).

In one study, Hurtado, Grüter, Marchman, and Fernald (2013) investigated bilingual infants' processing efficiency of familiar words (for another similar study see 
Marchman, Fernald, \& Hurtado, 2010). The variant of the procedure they used is called "looking while listening" because it emphasizes in-the moment language processing (Fernald, Zangl, Portillo, \& Marchman, 2008). In separate testing sessions in each of their two languages, Spanish-English bilingual toddlers aged 30-36 months were tested on highly familiar words such as apple and balloon, and their Spanish translations. On each trial, infants heard a familiar carrier phrase that contained the target word such as, "Where is the apple?" At the same time, infants saw picture pairs on a television screen, one of which was the target word and one of which was a distractor (e.g. an apple and a truck). Researchers coded videotapes of infants' eye movements frame by frame, determining which of the two images they looked at, and crucially, at what point during the trial their attention shifted from one picture to the other. Reaction time, a proxy for processing efficiency, was operationalized as infants' latency to shift to the correct picture on trials where they had initially fixated on the distractor. Bilingual infants' processing efficiency in each language was related to their exposure to that particular language, which in turn predicted later vocabulary size.

Another implementation of the intermodal preferential looking paradigm has investigated how bilingual infants respond to novel, unknown words. Monolingual infants and children show a mutual exclusivity heuristic, whereby they disambiguate an unfamiliar word by expecting it to refer to an unfamiliar picture rather than a familiar picture (Halberda, 2003; Markman \& Wachtel, 1988). Using the method devised by Halberda (2003), Byers-Heinlein and Werker (2009) investigated whether bilinguals and trilinguals show disambiguation from the same age as monolinguals. Infants were shown pairs of 
pictures on an eye-tracking monitor. Some pairs were familiar (ball-car) and some pairs contained a novel object (shoe-phototube). During a silent baseline, infants' overall tendency to look at each object was measured. On familiar label trials, infants heard a sentence labeling a familiar object, e.g. "Where is the car?" and on disambiguation trials, infants heard a sentence labeling a novel object, e.g. "Where is the nil?" The dependent variable was the proportion of time that infants spent looking at the labeled picture. Monolingual, bilingual, and trilingual infants looked to the target significantly above baseline on familiar label trials. However, on disambiguation trials, only monolinguals looked to the novel object significantly above chance, with bilinguals showing a marginally significant looking to the novel object, and trilingual performing at chance. Subsequent studies have used a similar method to replicate and extend this basic finding that bilingual infants are less likely to show disambiguation than monolinguals (Byers-Heinlein \& Werker, 2013; Houston-Price et al., 2010).

A third recent application of the preferential looking method is in priming studies (Arias-Trejo \& Plunkett, 2009 for priming with monolingual infants; see Styles \& Plunkett, 2009). In such studies, infants hear a prime sentence such as "I like the dog," and then a related target word e.g. "cat", or an unrelated target, e.g. "cookie". Infants' task is to look towards the referent of the target, which appears on the screen paired with the distractor (e.g. a cat and a truck). Evidence for priming is found if infants look longer at the target object on trials with a related than with an unrelated prime. Using this paradigm with Mandarin-English bilingual toddlers, Singh (2013) varied both the relation of the target and prime (e.g. related vs. unrelated words), the language of the target and the prime 
(English and Mandarin), and consequently the language match between prime and target

(e.g. same-language vs. different language). Within and cross-language priming was observed only when the prime was in the dominant language. In another study, Von Holzen and Mani (2012) tested phonological priming through translation in German learners exposed to English at daycare. A priming effect was found both when primetarget pairs were phonologically related (e.g. English slide and German kleid), and when the translation of the prime was phonologically related to the target (eg. leg primed stein because the German word for leg is bein).

\section{Procedures using brain-based measures}

While most experimental research to date with bilingual infants has used the behavioral techniques discussed above, a handful of studies have used brain-based measures. In particular, event related potentials (ERPs) have been used in several studies of young bilinguals. In ERP studies, infants wear a flexible cap of electrodes, which record electrical activity on the scalp. Various sound stimuli are played to infants, time-locked brain responses are recorded, and infants' brain responses to different types of stimuli are compared. For example, Conboy and Mills (2006) examined bilingual infants' brain responses to dominant and non-dominant language words. Infants showed more mature patterns of ERPs to words in the dominant language. Several other studies have used ERPs to examine infants' discrimination of speech sounds (Garcia-Sierra et al., 2011; Shafer et al., 2011; Shafer, Yu, \& Garrido-Nag, 2012). Other studies with bilingual infants have correlated ERP responses with complementary measures such as pupil dilation (Kuipers \& Thierry, 2013; but see Sebastián-Gallés, 2013). 
Functional near-infrared spectroscopy (fNIRS) is an emerging technology for understanding infant language processing and cognition (Gervain et al., 2011). In fNIRS, infants are fitted with an array of light emitters and detectors that are placed on the scalp. Light is shone through the skull to the cortex of the brain. Because oxygenated and deoxygenated hemoglobin have different patterns of oxygen absorption and refraction, the light that returns to the detectors provides an index of how much oxygen is present in a given area of the brain. Only one study to date including bilingual infants has used this technology (Petitto et al., 2011), but this approach is likely to become increasingly common in the study of bilingual newborns and young infants.

\section{Considerations in choosing stimuli for experimental studies}

A crucial issue in the design of experimental studies with bilingual infants is stimulus choice. Researchers studying bilingual infants face many of the same issues in stimulus choice as those who study monolingual infants. For example, they must consider salience of different stimuli, whether to use infant-directed or adult-directed speech, infants' likely knowledge of words used in a study, etc. Further, they must consider issues faced by adult bilingualism researchers, word frequency, cognate status, etc.

Additionally, in studies of bilingual infants, researchers must decide which language infants should be tested in. One possibility if a homogeneous sample is used is to test infants in both of their native languages. However, due to infants' limited attention spans, as well as order effects, this approach can be challenging. Another possibility is to choose a single language of testing. For heterogeneous samples, this will be the language that is common across infants. For homogeneous samples, the choice is trickier. 
Researchers can test all infants in their dominant language, test all infants in the same language, or test infants in a randomly assigned language. The choice will depend on the research question, and the availability and comparability of stimuli in different languages.

Even when stimuli are presented in a single language, there is evidence that different results can be obtained if stimuli are produced in a "monolingual" vs. a "bilingual" manner. For example, as mentioned in the discussion of the Switch task, two studies using nearly identical methods tested bilingual infants' ability to learn minimal pair words. In one study, bilinguals succeeded at 17-months (Mattock et al., 2010), while in the other infants did not succeed until 20-months (Fennell \& Werker, 2003). Why were the results divergent? A key difference between the studies was the manner in which the stimuli were produced. In the former study (Mattock et al., 2010), words were produced by a bilingual speaker, and their phonetic values were intermediate between the two languages. In the latter study (Fennell \& Werker, 2003), a monolingual speaker produced the stimuli in a monolingual manner. These very subtle differences are thought to have affected infants' performance on the task (Werker, Byers-Heinlein, \& Fennell, 2009).

\section{Conclusions}

Bilingual infants provide a fascinating window into the earliest roots of bilingualism, but they can be a challenging population to study. Over the past 20 years, research with young bilinguals has grown exponentially, due in part to the application of experimental and parental-report methods to bilingual infants. These methods complement numerous other approaches towards understanding early bilingualism such as diary studies (De Houwer, 1995), analyses of existing corpora (Corrigan, 2012; 
MacWhinney, 2000), and new methods for automated analysis of continuous recordings

(Naigles, 2012). Beyond the methods described here, emerging technologies and methodological innovations are likely to add to the toolkit of infant bilingualism researchers in coming years. 


\section{References}

Albareda-Castellot, B., Pons, F., \& Sebastián-Gallés, N. (2011). The acquisition of phonetic categories in bilingual infants: New data from an anticipatory eye movement paradigm. Developmental Science, 14(2), 395-401. doi:10.1111/j.1467-

7687.2010.00989.x

Arias-Trejo, N., \& Plunkett, K. (2009). Lexical-semantic priming effects during infancy. Philosophical Transactions of the Royal Society B: Biological Sciences, 364(1536), 3633-3647. doi:10.1098/rstb.2009.0146

Barron-Hauwaert, S. (2004). Language strategies for bilingual families: The one-parentone-language approach. Clevedon, UK: Multilingual Matters.

Bergelson, E., \& Swingley, D. (2012). At 6-9 months, human infants know the meanings of many common nouns. Proceedings of the National Academy of Sciences, 109(9), 3253-3258. doi:10.1073/pnas.1113380109

Bergelson, E., \& Swingley, D. (2013). The acquisition of abstract words by young infants. Cognition, 127(3), 391-397. doi:10.1016/j.cognition.2013.02.011

Bialystok, E., Luk, G., Peets, K. F., \& Yang, S. (2010). Receptive vocabulary differences in monolingual and bilingual children. Bilingualism: Language and Cognition, 13(04), 525-531. doi:10.1017/S1366728909990423

bilingual. (n.d.). Collins English Dictionary - Complete \& Unabridged 10th Edition. Retrieved from http://dictionary.reference.com/browse/bilingual

Blom, E., \& Unsworth, S. (2010). Experimental Methods in Language Acquisition Research. Philadelphia, PA: John Benjamins. 
Bosch, L., \& Ramon-Casas, M. (2011). Variability in vowel production by bilingual speakers: Can input properties hinder the early stabilization of contrastive categories? Journal of Phonetics, 39(4), 514-526. doi:10.1016/j.wocn.2011.02.001

Bosch, L., \& Sebastián-Gallés, N. (1997). Native-language recognition abilities in 4-monthold infants from monolingual and bilingual environments. Cognition, 65(1), 33-69. doi:10.1016/S0010-0277(97)00040-1

Bosch, L., \& Sebastián-Gallés, N. (2001). Evidence of early language discrimination abilities in infants from bilingual environments. Infancy, 2(1), 29-49. doi: 10.1207/S15327078IN0201_3

Bosch, L., \& Sebastián-Gallés, N. (2003). Simultaneous bilingualism and the perception of a language-specific vowel contrast in the first year of life. Language and Speech, 46(23), 217-243. doi:10.1177/00238309030460020801

Bosch, L., Figueras, M., Teixidó, M., \& Ramon-Casas, M. (2013). Rapid gains in segmenting fluent speech when words match the rhythmic unit: Evidence from infants acquiring syllable-timed languages. Frontiers in Psychology, 4(106); 1-12.

doi:10.3389/fpsyg.2013.00106/abstract

Burns, T. C., Yoshida, K. A., Hill, K., \& Werker, J. F. (2007). The development of phonetic representation in bilingual and monolingual infants. Applied Psycholinguistics, 28(03), 455-474. doi:10.1017/S0142716407070257

Byers-Heinlein, K. (2013). Parental language mixing: Its measurement and the relation of mixed input to young bilingual children's vocabulary size. Bilingualism: Language and Cognition, 16(01), 32-48. doi: 10.1017/S1366728912000120 
Byers-Heinlein, K., \& Fennell, C. T. (under review). Perceptual narrowing in the context of increased variation: Insights from bilingual infants. Developmental Psychobiology.

Byers-Heinlein, K., \& Werker, J. F. (2009). Monolingual, bilingual, trilingual: Infants' language experience influences the development of a word-learning heuristic. Developmental Science, 12(5), 815-823. doi:10.1111/j.1467-7687.2009.00902.x

Byers-Heinlein, K., \& Werker, J. F. (2013). Lexicon structure and the disambiguation of novel words: Evidence from bilingual infants. Cognition, 128(3), 407-416. doi:10.1016/j.cognition.2013.05.010

Byers-Heinlein, K., Burns, T. C., \& Werker, J. F. (2010). The roots of bilingualism in newborns. Psychological Science, 21(3), 343-348. doi:10.1177/0956797609360758

Byers-Heinlein, K., Fennell, C. T., \& Werker, J. F. (2013). The development of associative word learning in monolingual and bilingual infants. Bilingualism: Language and Cognition, 16(1), 198-205. doi: 10.1017/S1366728912000417

Colombo, J., \& Mitchell, D. W. (2009). Infant visual habituation. Neurobiology of Learning and Memory, 92(2), 225-234. doi:10.1016/j.nlm.2008.06.002

Conboy, B. T., \& Mills, D. L. (2006). Two languages, one developing brain: Event-related potentials to words in bilingual toddlers. Developmental Science, 9(1), F1-F12. doi:10.1111/j.1467-7687.2005.00453

Conboy, B. T., \& Thal, D. (2006). Ties between the lexicon and grammar: Cross-sectional and longitudinal studies of bilingual toddlers. Child Development, 77(3), 712-735. doi:10.1111/j.1467-8624.2006.00899.x

Corrigan, R. (2012). Using the CHILDES Database. In E. Hoff (Ed.), Research Methods in 
Child Language: A Practical Guide (pp. 271-284). Malden, MA: Wiley-Blackwell.

Curtin, S., Byers-Heinlein, K., \& Werker, J. F. (2011). Bilingual beginnings as a lens for theory development: PRIMIR in focus. Journal of Phonetics, 39(4), 492-504. doi:10.1016/j.wocn.2010.12.002

David, A., \& Wei, L. (2008). Individual differences in the lexical development of FrenchEnglish bilingual children. International Journal of Bilingual Education and Bilingualism, 11(5), 598-618. doi:10.1080/13670050802149200

De Houwer, A. (1990). The Acquisition of Two Languages from Birth. Cambridge, MA: Cambridge University Press.

De Houwer, A. (1995). Bilingual language acquisition. In P. Fletcher \& B. MacWhinney (Eds.), Handbook of Child Language (pp. 219-250). Oxford, UK: Blackwell.

De Houwer, A. (1998). By way of introduction: Methods in studies of bilingual first language acquisition. International Journal of Bilingualism, 2(3), 249-263. doi:10.1177/136700699800200301

De Houwer, A. (2007). Parental language input patterns and children's bilingual use. Applied Psycholinguistics, 28(03), 411-424. doi:10.1017/S0142716407070221

De Houwer, A., \& Bornstein, M. H. (2003). Balancing on the tightrope: Language use patterns in bilingual families with young children. Presented at the 4th International Symposium on Bilingualism, Tempe, AZ.

De Houwer, A., Bornstein, M. H., \& De Coster, S. (2006). Early understanding of two words for the same thing: A CDI study of lexical comprehension in infant bilinguals. International Journal of Bilingualism, 10(3), 331-347. doi:10.1111/j.1467- 
8624.2006.00899.x

De Houwer, A., Bornstein, M. H., \& Putnick, D. L. (2013). A bilingual-monolingual comparison of young children's vocabulary size: Evidence from comprehension and production. Applied Psycholinguistics, 1-23. doi:10.1017/S0142716412000744

Döpke, S. (1998). Can the principle of one person-one language be disregarded as unrealistically elitist? Australian Review of Applied Linguistics, 21(1), 41-56.

Fennell, C. T. (2012). Habituation Procedures. In E. Hoff (Ed.), Research Methods in Child Language: A Practical Guide (pp. 3-16). Malden, MA: Wiley-Blackwell.

Fennell, C. T., \& Werker, J. F. (2003). Early word learners' ability to access phonetic detail in well-known words. Language and Speech, 46(2-3), 245-264. doi:10.1177/00238309030460020901

Fennell, C. T., Byers-Heinlein, K., \& Werker, J. F. (2007). Using speech sounds to guide word learning: The case of bilingual infants. Child Development, 78(5), 1510-1525. doi: $10.1111 / j .1467-8624.2007 .01080 . x$

Fenson, L., Dale, P. S., Steven Reznick, J., Thal, D. J., Bates, E., Hartung, J. P., et al. (1993). MacArthur Communicative Development Inventories (1st ed.). Baltimore, MD: Brookes.

Fenson, L., Marchman, V. A., Thal, D. J., Dale, P. S., Steven Reznick, J., \& Bates, E. (2007). MacArthur-Bates Communicative Development Inventories (2nd ed.). Baltimore, MD: Brookes.

Fernald, A. (1985). Four-month-old infants prefer to listen to motherese. Infant Behavior and Development, 8(2), 181-195. doi:10.1016/s0163-6383(85)80005-9 
Fernald, A., Zangl, R., Portillo, A. L., \& Marchman, V. A. (2008). Looking while listening: Using eye movements to monitor spoken language comprehension by infants and young children. In I. A. Sekerina, E. M. Fernandez, \& H. Clahsen (Eds.), Developmental Psycholinguistics: One-line methods in children's language processing (pp. 97-135). Amsterdam: John Benjamins Publishing Company.

Garcia-Sierra, A., Rivera-Gaxiola, M., Percaccio, C. R., Conboy, B. T., Romo, H., Klarman, L., et al. (2011). Bilingual language learning: An ERP study relating early brain responses to speech, language input, and later word production. Journal of Phonetics, 39(4), 546-557. doi:10.1016/j.wocn.2011.07.002

Gervain, J., \& Werker, J. F. (2013). Prosody cues word order in 7-month-old bilingual infants. Nature Communications, 4, 1490-1496. doi:10.1038/ncomms2430

Gervain, J., Mehler, J., Werker, J. F., Nelson, C. A., Csibra, G., Lloyd-Fox, S., et al. (2011). Near-infrared spectroscopy: A report from the McDonnell infant methodology consortium. Accident Analysis and Prevention, 1(1), 22-46. doi:10.1016/j.dcn.2010.07.004

Golinkoff, R. M., Hirsh-Pasek, K., Cauley, K. M., \& Gordon, L. (1987). The eyes have it: Lexical and syntactic comprehension in a new paradigm. Journal of Child Language, 14(1), 23-45. doi:10.1017/S030500090001271X

Golinkoff, R. M., Ma, W., Song, L., \& Hirsh-Pasek, K. (2013). Twenty-five years using the intermodal preferential looking paradigm to study language acquisition: What have we learned? Perspectives on Psychological Science, 8(3), 316-339. doi:10.1177/1745691613484936 
Grosjean, F. M. J. (1989). Neurolinguists, beware! The bilingual is not two monolinguals in one person. Brain and Language, 36(1), 3-15. doi:10.1016/0093-934X(89)90048-5

Halberda, J. (2003). The development of a word-learning strategy. Cognition, 87(1), B23B34. doi:10.1016/S0010-0277(02)00186-5

Hoff, E. (Ed.). (2012). Research Methods in Child Language: A Practical Guide. Malden, MA: Wiley-Blackwell.

Hoff, E., \& Luz Rumiche, R. (2012). Studying Children in Bilingual Environments. In Studying children in bilingual environments (pp. 300-316). Oxford, UK: Wiley-Blackwell. doi:10.1002/9781444344035.ch20

Hoff, E., Core, C., Place, S., Rumiche, R., Señor, M., \& Parra, M. (2012). Dual language exposure and early bilingual development. Journal of Child Language, 39(1), 1-27. doi:10.1017/S0305000910000759

Houston-Price, C., Caloghiris, Z., \& Raviglione, E. (2010). Language experience shapes the development of the mutual exclusivity bias. Infancy, 15(2), 125-150. doi:10.1111/j.1532-7078.2009.00009.x

Hudon, T. M., Fennell, C. T., \& Hoftyzer, M. (2013). Quality not quantity of television viewing is associated with bilingual toddlers' vocabulary scores. Infant Behavior and Development, 36(2), 245-254. doi:10.1016/j.infbeh.2013.01.010

Hunter, M. A., \& Ames, E. W. (1988). A multifactor model of infant preferences for novel and familiar stimuli. Advances in Infancy Research, 5, 69-95.

Hurtado, N., Gruter, T., Marchman, V. A., \& Fernald, A. (2013). Relative language exposure, processing efficiency and vocabulary in Spanish-English bilingual toddlers. 
Bilingualism: Language and Cognition, 1-14. doi:10.1017/S136672891300014X

Junker, D., \& Stockman, I. (2002). Expressive vocabulary of German-English bilingual toddlers. American Journal of Speech-Language Pathology, 11(4), 381-394.

Jusczyk, P. W. (1985). The high-amplitude sucking technique as a methodological tool in speech perception research. In G. Gottlieb \& N. A. Krasnegor (Eds.), Measurement of audition and vision in the first year of postnatal life: A methodological overview (pp. 195-222). Westport, CT: Ablex Publishing.

Kemler Nelson, D. G., Jusczyk, P. W., Myers, J., Turk, A., \& Gerken, L. (1995). The head-turn preference procedure for testing auditory perception. Infant Behavior and Development, 18(1), 111-116. doi:10.1016/0163-6383(95)90012-8

Kuipers, J. R., \& Thierry, G. (2013). ERP-pupil size correlations reveal how bilingualism enhances cognitive flexibility. Cortex. doi:10.1016/j.cortex.2013.01.012

Kovács, Á. M., \& Mehler, J. (2009). Cognitive Gains in 7-Month-Old Bilingual Infants. Proceedings of the National Academy of Sciences, 106(16), 6556-6560. doi:10.1073/pnas.0811323106

Liu, L., \& Kager, R. (2013). How bilingualism alters non-tone-learning infants' perception in the first year of life (pp. 1-10). Presented at the 37th Annual Boston University Conference on Child Language Development.

Lloyd-Fox, S., Blasi, A., \& Elwell, C. E. (2010). Illuminating the developing brain: the past, present and future of functional near infrared spectroscopy. Neuroscience \& Biobehavioral Reviews, 34(3), 269-284. doi:10.1016/j.neubiorev.2009.07.008 MacWhinney, B. (2000). The CHILDES Project: The database (3rd ed.). Mahwah, NJ: 
Lawrence Erlbaum.

Marchman, V. A., \& Martinez-Sussmann, C. (2002). Concurrent validity of caregiver/parent report measures of language for children who are learning both English and Spanish. Journal of Speech, Language and Hearing Research, 45(5), 983. doi:10.1044/1092$4388(2002 / 080)$

Marchman, V. A., Fernald, A., \& Hurtado, N. (2010). How vocabulary size in two languages relates to efficiency in spoken word recognition by young Spanish-English bilinguals. Journal of Child Language, 37(4), 817-840. doi:10.1017/S0305000909990055

Markman, E. M., \& Wachtel, G. F. (1988). Children's use of mutual exclusivity to constrain the meanings of words. Cognitive Psychology, 20(2), 121-157. doi:10.1016/00100285(88)90017-5

Mattock, K., Polka, L., Rvachew, S., \& Krehm, M. (2010). The first steps in word learning are easier when the shoes fit: Comparing monolingual and bilingual infants. Developmental Science, 13(1), 229-243. doi:10.1111/j.1467-7687.2009.00891.x

McMurray, B., \& Aslin, R. N. (2004). Anticipatory eye movements reveal infants' auditory and visual categories. Infancy, 6(2), 203-229. doi:10.1207/s15327078in0602_4

Morton, J. B., \& Harper, S. N. (2009). Bilinguals show an advantage in cognitive control the question is why. Developmental Science, 12(4), 502-503. doi:10.1111/j.14677687.2009.00867.x

Naigles, L. R. (2012). Not Sampling, Getting It All. In E. Hoff (Ed.), Research Methods in Child Language: A Practical Guide (pp. 240-253). Malden, MA: Wiley-Blackwell.

Pearson, B. Z. (1998). Assessing lexical development in bilingual babies and toddlers. 
International Journal of Bilingualism, 2(3), 347-372.

doi:10.1177/136700699800200305

Pearson, B. Z. (2008). Raising a Bilingual Child. New York, NY: Random House.

Pearson, B. Z., Fernández, S. C., \& Oller, D. (1993). Lexical development in bilingual infants and toddlers: Comparison to monolingual norms. Language Learning, 43(1), 93-120. doi:10.1111/j.1467-1770.1993.tb00174.x

Pearson, B. Z., Fernández, S. C., \& Oller, D. (1995). Cross-language synonyms in the lexicons of bilingual infants: One language or two? Journal of Child Language, 22(2), 345-368. doi:10.1017/S030500090000982X

Petitto, L. A., Berens, M. S., Kovelman, I., Dubins, M. H., Jasinska, K., \& Shalinsky, M. (2011). The "Perceptual Wedge Hypothesis" as as the basis for bilingual babies' phonetic processing advantage: New insights from fNIRS brain imaging. Brain and Language, 121(2), 1-14. doi:10.1016/j.bandl.2011.05.003

Place, S., \& Hoff, E. (2010). Properties of dual language exposure that influence two-yearolds' bilingual proficiency. Child Development, 82(6), 1834-1849. doi:10.1111/j.14678624.2011.01660.x

Poulin-Dubois, D., Bialystok, E., Blaye, A., Polonia, A., \& Yott, J. (2012). Lexical access and vocabulary development in very young bilinguals. International Journal of Bilingualism, 17(1), 1-15. doi:10.1177/1367006911431198

Poulin-Dubois, D., Blaye, A., Coutya, J., \& Bialystok, E. (2011). The effects of bilingualism on toddlers' executive functioning. Journal of Experimental Child Psychology, 108(3), 567-579. doi:10.1016/j.jecp.2010.10.009 
Ramon-Casas, M., Swingley, D., Sebastián-Gallés, N., \& Bosch, L. (2009). Vowel categorization during word recognition in bilingual toddlers. Cognitive Psychology, 59(1), 96-121. doi:10.1016/j.cogpsych.2009.02.002

Ronjat, Jules. Le développement du langage observé chez un enfant bilingue. Champion, 1913.

Sebastián-Gallés, N. (2013). Eyes wide shut: Linking brain and pupil in bilingual and monolingual toddlers. Trends in Cognitive Sciences, 17(5), 197-198. doi:10.1016/j.tics.2013.03.002

Sebastián-Gallés, N., \& Bosch, L. (2002). Building phonotactic knowledge in bilinguals: Role of early exposure. Journal of Experimental Psychology: Human Perception and Performance, 28(4), 974-989. doi:10.1037//0096-1523.28.4.974

Sebastián-Gallés, N., \& Bosch, L. (2009). Developmental shift in the discrimination of vowel contrasts in bilingual infants: Is the distributional account all there is to it? Developmental Science, 12(6), 874-887. doi:10.1111/j.1467-7687.2009.00829.x

Sebastián-Gallés, N., Albareda-Castellot, B., Weikum, W. M., \& Werker, J. F. (2012). A bilingual advantage in visual language discrimination in infancy. Psychological Science, 23(9), 994-999. doi:10.1177/0956797612436817

Sebastián-Gallés, N., Bosch, L., \& Pons, F. (2008). Early bilingualism. Encyclopedia of infant and early childhood development, 172-182.

Shafer, V. L., Yu, Y. H., \& Datta, H. (2011). The development of English vowel perception in monolingual and bilingual infants: Neurophysiological correlates. Journal of Phonetics, 39(4), 527-545. doi:10.1016/j.wocn.2010.11.010 
Shafer, V. L., Yu, Y. H., \& Garrido-Nag, K. (2012). Neural mismatch indices of vowel discrimination in monolingually and bilingually exposed infants: Does attention matter? Neuroscience Letters, 526(1), 10-14. doi:10.1016/j.neulet.2012.07.064

Sheng, L., Lu, Y., \& Kan, P. F. (2011). Lexical development in Mandarin-English bilingual children. Bilingualism: Language and Cognition, 1-9. doi:10.1017/S1366728910000647

Singh, L. (2013). One world, two languages: Cross-language semantic priming in bilingual toddlers. Child Development. doi:10.1111/cdev.12133

Singh, L., \& Foong, J. (2012). Influences of lexical tone and pitch on word recognition in bilingual infants. Cognition, 124(2), 128-142. doi:10.1016/j.cognition.2012.05.008

Stager, C. L., \& Werker, J. F. (1997). Infants listen for more phonetic detail in speech perception than in word-learning tasks. Nature, 388(6640), 381-382. doi:

$10.1038 / 41102$

Styles, S. J., \& Plunkett, K. (2009). How do infants build a semantic system? Language and Cognition, 1(1), 1-24. doi:10.1515/LANGCOG.2009.001

Sundara, M., \& Scutellaro, A. (2010). Rhythmic distance between languages affects the development of speech perception in bilingual infants. Journal of Phonetics, 39(4) 505513. doi:10.1016/j.wocn.2010.08.006

Sundara, M., Polka, L., \& Molnar, M. (2008). Development of coronal stop perception: Bilingual infants keep pace with their monolingual peers. Cognition, 108(1), 232-242. doi:10.1016/j.cognition.2007.12.013

Teinonen, T., Fellman, V., Näätänen, R., Alku, P., \& Huotilainen, M. (2009). Statistical 
language learning in neonates revealed by event-related brain potentials. BMC Neuroscience, 10(1), 21. doi:10.1186/1471-2202-10-21

Thordardottir, E. (2011). The relationship between bilingual exposure and vocabulary development. International Journal of Bilingualism, 1-21. doi:10.1177/1367006911403202

Umbel, V., Pearson, B. Z., Fernández, M., \& Oller, D. (1992). Measuring bilingual children's receptive vocabularies. Child Development, 63(4), 1012-1020.

Unsworth, S. (2013). Assessing the role of current and cumulative exposure in simultaneous bilingual acquisition: The case of Dutch gender. Bilingualism: Language and Cognition, 16(01), 86-110. doi:10.1017/S1366728912000284

Vihman, M. M., Thierry, G., Lum, J., Keren-Portnoy, T., \& Martin, P. (2007). Onset of word form recognition in English, Welsh, and English-Welsh bilingual infants. Applied Psycholinguistics, 28(3), 475-493. doi:10.1017/S0142716407070269

Von Holzen, K., \& Mani, N. (2012). Language nonselective lexical access in bilingual toddlers. Journal of Experimental Child Psychology, 113(4), 569-586. doi:10.1016/j.jecp.2012.08.001

Weikum, W. M., Vouloumanos, A., Navarra, J., Soto-Faraco, S., Sebastián-Gallés, N., \& Werker, J. F. (2007). Visual language discrimination in infancy. Science, 316(5828), 1159. doi:10.1126/science. 1137686

Weisleder, A., \& Fernald, A. (2011). Variation in early language experience influences processing and language growth. Presented at the CUNY Conference on Human Sentence Processing. 
Werker, J. F. (2012). Perceptual foundations of bilingual acquisition in infancy. Annals of the New York Academy of Sciences, 1251(1), 50-61. doi:10.1111/j.1749-

6632.2012.06484.x

Werker, J. F., \& Byers-Heinlein, K. (2008). Bilingualism in infancy: First steps in perception and comprehension. Trends in Cognitive Sciences, 12(4), 144-151.

doi:10.1016/j.tics.2008.01.008

Werker, J. F., Byers-Heinlein, K., \& Fennell, C. T. (2009). Bilingual beginnings to learning words. Philosophical Transactions of the Royal Society B: Biological Sciences, 364(1536), 3649-3663. doi:10.1098/rstb.2009.0105

Werker, J. F., Cohen, L., Lloyd, V., Casasola, M., \& Stager, C. (1998). Acquisition of wordobject associations by 14-month-old infants. Developmental Psychology, 34(6), 12891309. 
Box 1: Best Practices for Characterizing Language Exposure in Bilingual Infants

a) Use a detailed parent interview rather than relying on a one-off parental estimate.

b) Ask about input from all individuals who interact with the infant, including parents, other family members, and childcare providers.

c) Exclude indirect exposure such as television.

d) Assess continuity of exposure by asking about travel and changes in caregiving arrangements.

e) Consider both cumulative and current exposure in assessing language exposure.

f) Use a-priori and consistent definitions for "bilingual" groups, specifying requirements for onset of exposure and amount of exposure. 


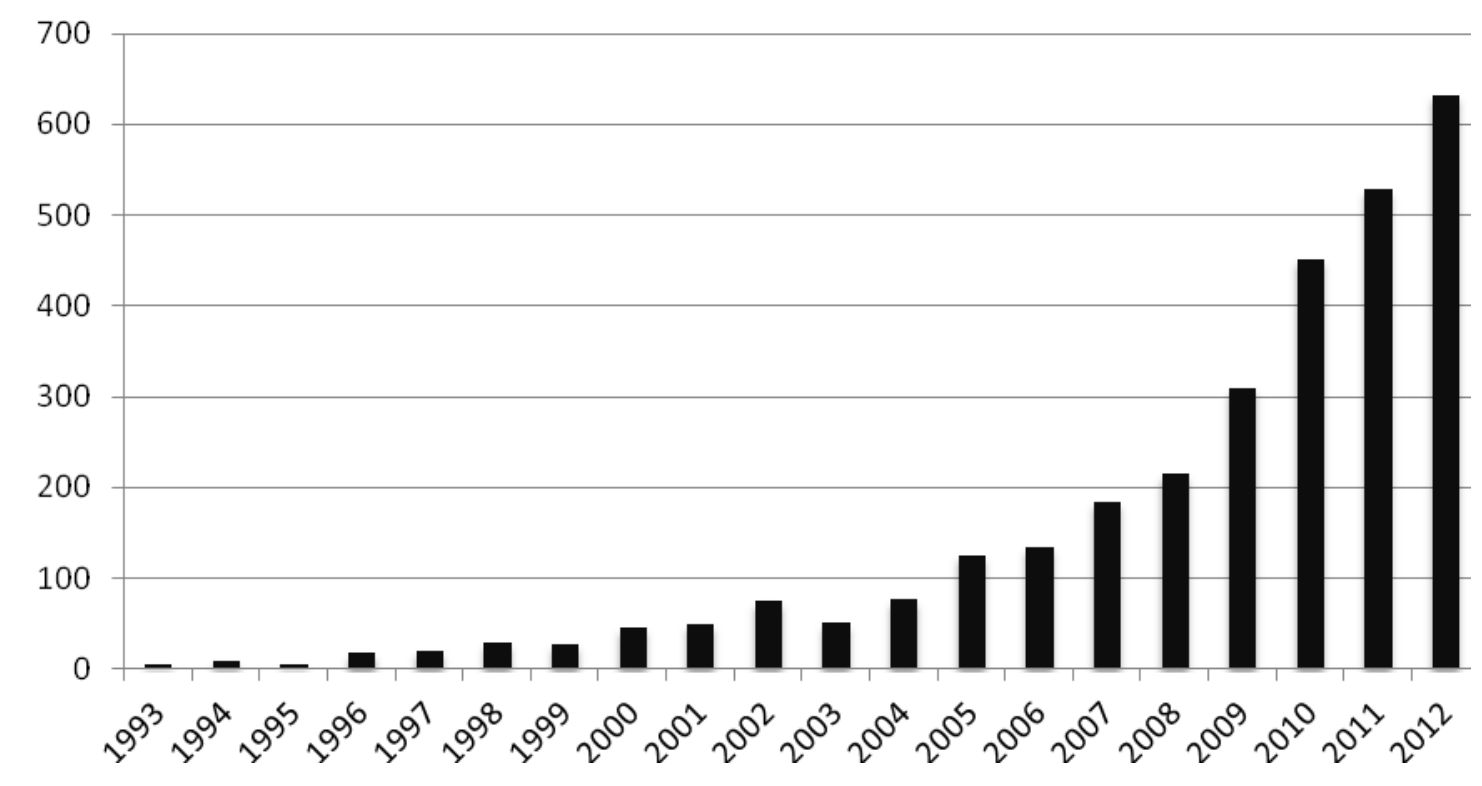

Figure 1. Yearly citations from 1993-2012 of papers with keywords "infant" and "bilingual". Retrieved from the Web of Science database (Thomson Reuters). 


\section{English French}
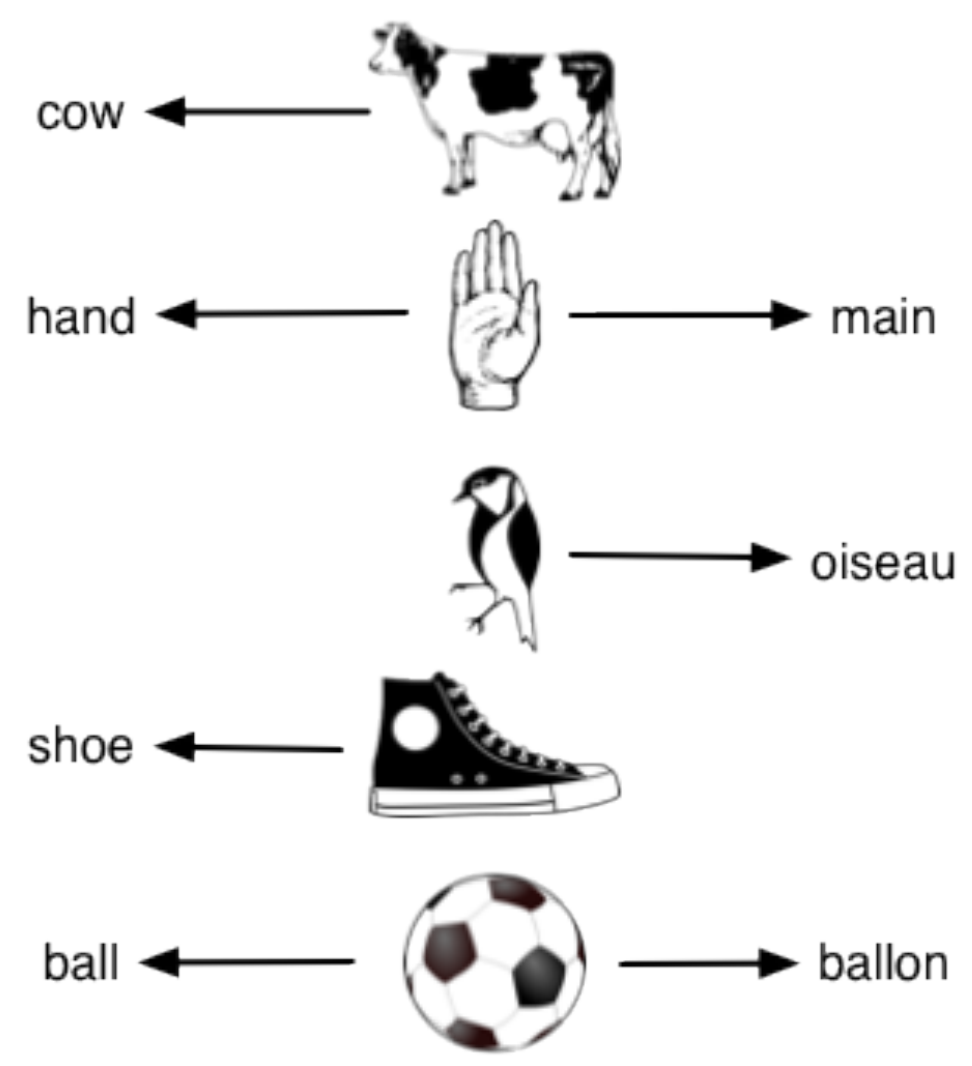

Total conceptual vocabulary: 5

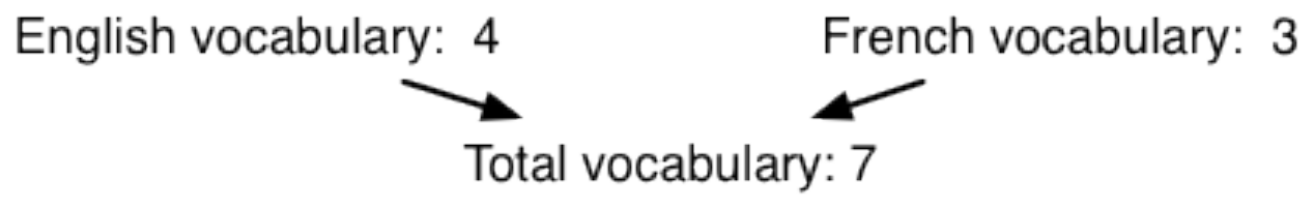

Figure 2. An illustration of different measures of vocabulary size in a hypothetical FrenchEnglish bilingual infant. English vocabulary counts the English words known by the infant. French vocabulary counts the French words known by the infant. Total vocabulary sums the English and French words known by the infant. Total conceptual vocabulary counts the total number of concepts lexicalized by the infant, which is equivalent to the total vocabulary minus the number of words whose meanings is captured by its translation equivalent. 